\section{UMA CONVERSA NO COTIDIANO ESCOLAR NO/DO ENSINO MÉDIO, CURRÍCULOS PENSADOSPRATICADOS E MOVIMENTOS DE (RE)EXISTÊNCIA}

\author{
A CONVERSATION IN EVERYDAY HIGH SCHOOL LIFE, PLANNED AND EXECUTED CURRICULUMS AND \\ MOVEMENTS OF (RE)EXISTENCE
}

\author{
Manoel de Souza Araújo \\ Rafael Marques Gonçalves ${ }^{2}$
}

\begin{abstract}
Resumo: A proposta desse artigo busca desinvibilizar as táticas cotidianas de um grupo de professores de uma escola da rede estadual de Ensino Médio, de uma cidade do interior do estado do Acre. Destacase, nessa análise, o currículo e a prática dos professores que pensam/fazem os currículos pensados/praticados nos cotidianos escolares. A partir do mergulho no/do/com o cotidiano escolar, tomase como elemento metodológico os encontros e as conversas. Aposta-se que o reordenamento, sobretudo das políticaspráticas, instiga movimentos de (re)existência, com os quais os professores da escola lutam por sua autonomia, ainda que utópica e momentânea. O estudo ocorre no contexto de emergência de uma reforma curricular prescritiva oriunda da Base Nacional Comum Curricular, em processo de implementação no Brasil, e que resulta na imposição de práticas, avaliações e processos formativos no Ensino Médio.
\end{abstract}

Palavras-chave: Cotidiano escolar. Currículos. Ensino Médio.

\begin{abstract}
The aim of this article is to display everyday practices of a group of teachers from a public high school, located in Acre's countryside. It highlights the curriculum and actions that teachers take during its elaboration at everyday work. From the deepening view on scholar routine, meetings and discussions are used as methodological elements. The bet is on a rearrengement, especially practical policies, that instigates movementes of (re)existence, which school teachers fight for autonomy, even though utopian and momentary. This occurs in a context of emerging prescribed curricular reform, originating from the National Common Curricular Base, in the implementation process in Brazil, which results in the imposition of practices, tests and training processes in high school.
\end{abstract}

Keywords: School life. School's curriculum. High school.

Resumen: La propuesta de este artículo busca hacer visible las tácticas diarias de um grupo de maestros de una escuela secundaria estatal, en una ciudad en el interior del estado de Acre. En este análisis, se destaca el currículum escolar y la práctica de los maestros que piensan y hacen que los planes de estudio sean planificados y realizados em la vida diaria de la escuela. Desde la zambullida hacia / desde / con la rutina escolar, las reuniones y conversaciones se toman como elemento metodológico. Se apuesta a que la reorganización, especialmente de las políticas prácticas, instiga movimientos de (re)existencia, con los cuales los maestros de escuela luchan por su autonomía, incluso si son utópicos y momentáneos. El estudio se lleva a cabo en el contexto de la aparición de uma reforma curricular prescriptiva originada en la Base Curricular Común Nacional, que se está implementando en Brasil, y que resulta en la imposición de prácticas, evaluaciones y procesos de capacitación en la escuela secundaria.

Palabras clave: Vida escolar. Currículum. Escuela secundaria.

\footnotetext{
1 Mestrando no Programa de Pós-Graduação em Educação da Universidade Federal do Acre. E-mail: manoelaraujoczs@gmail.com. Orcid: http://orcid.org/0000-0003-0991-3327.

${ }^{2}$ Doutor em Educação pelo Programa de Pós-Graduação em Educação (ProPEd-CAPES 7), com ênfase em Currículo e Cotidiano Escolar, da Universidade do Estado do Rio de Janeiro e Professor Adjunto da Universidade Federal do Acre. E-mail: rafamg02@gmail.com. Orcid: http://orcid.org/0000-0002-9038-1542.
} 


\section{ABRINDO A CONVERSA}

Ninguém caminha sem aprender a caminhar, sem aprender a fazer o caminho caminhando, refazendo e retocando o sonho pelo qual se pôs a caminhar.

(Paulo Freire)

Nesse artigo, apresentamos os achados iniciais de uma pesquisa em curso, inserida no cotidiano escolar de uma escola estadual de Ensino Médio, no interior do Estado do Acre. Nessa pesquisa apostamos que, mesmo diante de propostas curriculares mais prescritivas, os professores usam táticas para viabilizar e visibilizar os conhecimentos presentes no ambiente escolar. Eles configuram, desse modo, um espaçotempo privilegiado para as tessituras de conhecimentos em rede e de ação contrahegemônica.

Ao tomarmos o cotidiano escolar como elemento que move uma pesquisa, não reduzimos esse a uma realidade social específica. Ele é visto como um instrumento para conhecer e compreender as diversas redes que se entrecruzam nas crenças, nos conhecimentos e nos valores que cada sujeito traz de suas vivências em múltiplas realidades sociais (GONÇALVES, 2018; GONÇALVES et al, 2020).

Para subsidiar essa pesquisa, optamos por realizar rodas de conversas (GONÇALVES, 2020) com professores da escola, entendendo as conversas como um espaçotempo pedagógico, rico e diferenciado, visto o nível de compreensão de seus participantes. Num primeiro momento, as falas podem ser vistas como destoantes e contraditórias. Porém, elas geram nos participantes um processo de reflexão, exigindo deles um pensar sobre suas próprias práticas e sobre as falas dos demais colegas.

Assim, é nesse processo de reflexão, que vai do pensarfazer pessoal ao pensarfazer dos demais participantes, proporcionado pelas rodas de conversas, que os sujeitos produzem um conhecimento prático próprio da instituição de ensino. Por esse caminho, a escola se constitui como espaço de aprendizagem não apenas dos alunos. Ela reverte-se em um espaço próprio e adequado para a aprendizagem também dos professores.

\section{CURRÍCULO E COTIDIANO ESCOLAR}

Conhecer é sempre um desejo presente no indivíduo, gerado por uma ausência que precisa ser superada ou preenchida do ponto de vista epistemológico. No entanto, sabemos que as realidades com que nos deparamos, nos espaçostempos, não se dão a conhecer de forma simples e organizada. Cada sujeito poderá compreendê-las por meio das redes de conhecimentos, crenças e valores que traz de suas culturas. A complexidade existente gera múltiplas realidades capazes de nos apresentar vieses para construirmos conhecimentos mediante as experiências.

Dessa forma, vamos compreendendo que o cotidiano, na esteira do propõe Certeau (1998), pode desvelar as complexidades existentes entre as redes de conhecimentos. $O$ autor define dois tipos de comportamentos que nos elucidam a dinâmica do cotidiano que, como espaçotempo, permite múltiplas relações, a saber: táticas e estratégias.

As táticas não definem práticas ou formas de organização social, não seguem uma lei ou se subjugam às condutas do lugar, enquanto as estratégias se materializam nas leis. Elas são capazes de criar formas de organização social e determinar que práticas aconteçam em lugares diferentes ao mesmo tempo. Em suma, "o que distingue as táticas das estratégias são os tipos de operações nesses espaços que as estratégias são capazes de produzir, mapear e impor, ao passo que as táticas só podem utilizá-los, manipular e alterar" (CERTEAU, 1998, p. 92).

Podemos dizer que, para Certeau, o cotidiano é o espaçotempo das realidades sociais. Nele, as relações e as experiências acontecem, se (re)inventam e se modificam. Também modificam aqueles que dele participam, não se limitando a determinado espaço, mas se materializando em várias realidades concomitantemente.

As tessituras sociais numa escola parcial são consideradas ricas na construção de conhecimento. Podem tornar-se potencializadas numa escola de tempo integral que trabalha com adolescentes (Ensino Médio), com toda uma carga de energia, em processo de formação e de fortalecimento de suas relações 
ISSN $1983-1579$

Doi: 10.22478/ufpb.1983-1579.2020v13n3.52791

http://periodicos.ufpb.br/ojs2/index.php

com o meio.

Ao falar de suas experiências em trabalhar na Escola Jovem de Tempo Integral, o Professor João descreve a respeito da vivência cotidiana como algo transformador. Assim ele expressa:

Prof. João - Foi a melhor [experiência] possível. Eu me encontrei aqui. O Ensino Integral era o modelo de sonhos que eu tinha, e foi transformador [...]. Eu, particularmente, mudei muito as minhas práticas em sala de aula. O Ensino Integral está me proporcionando isso que reflete no amadurecimento do nosso alunado.

A partir da fala do professor João, podemos inferir que a política da Escola Jovem de Tempo Integral pode viabilizar aos professores mais tempo para desenvolver seus trabalhos pedagógicos com os alunos. Isso porque passam mais tempo na escola, podendo, também, aumentar sua bagagem de conhecimento, seus rendimentos e inserção no mercado de trabalho ou, ainda, investir na continuação dos estudos.

O estar mais presente na escola proporciona muitas descobertas e faz o indivíduo sentir cada momento, cada experiência e cada história que ali se passa. É natural que haja o amadurecimento das pessoas que vivem/convivem esse/nesse contexto, tanto professores, como alunos e pais. As histórias contadasvividas são capazes de oportunizar conhecimentos para a vida que somente quem estiver mergulhado no cotidiano pode experimentar.

O currículo escolar, como política governamental normativa, se materializa no ambiente escolar, ou seja, no cotidiano, nas ações práticas dos professores dentro de um espaçotempo próprio. É no cotidiano escolar e no fazer dos professores que um determinado currículo ganha vida, não necessariamente o currículo oficial, mas o currículo ressignificado pelos professores a partir do oficial. $O$ pensarfazer do cotidiano escolar tem dinâmica própria em cada escola e em cada espaçotempo em que ele se realiza.

Para Oliveira (2016), mesmo que os praticantes da vida cotidiana estejam submetidos a regras sociais que não sejam produzidas por eles, aplicam no cotidiano uma reinterpretação delas. Isso ocorre de um modo bem próprio, causando intervenção e produzindo novas normatizações. Esse processo dáse a partir de entendimento construído entre os diversos grupos sociais.

O ambiente escolar, enquanto lócus de pesquisa cotidiana, é recheado de regras e normas que não são produzidas pelos atores da ação escolar, sejam elas de abrangência nacional ou regional. No entanto, a (re)leitura, a (re)interpretação e a aplicação dessas regras no "chão da escola", produzem efeitos particulares e próprios da/na instituição.

É fundamental compreender que as prescrições curriculares, a exemplo da Base Nacional Curricular Comum (BNCC), que têm abrangências nacional para as redes públicas e privadas, sofrerão alterações na sua aplicabilidade. As tessituras e redes de conhecimentos presentes no ambiente escolar são aplicadas por seus sujeitos, salvaguardando as tradições e as relações experimentadas e vividas nos espaçostempos da escola.

Nesse sentido, o "currículo oficial”, a BNCC, no caso, não será aplicada de modo mecânico no cotidiano escolar. Sofrerá reinterpretações e tomará os modos próprios do pensarfazer dos professores no cotidiano da escola. Logo, a relação entre currículo e cotidiano é o que dará vida real ao processo de aprendizagem. O cotidiano e as tessituras do pensarfazer construirão um novo tipo de currículo. Ele surgirá a partir daquele que vem prescrito, porém não restrito a ele, reafirmando a noção de cotidiano como espaçotempo de construção de conhecimento e de emancipação social.

Compreender o currículo na perspectiva do cotidiano, tendo como elementos as redes de conhecimentos que se entrelaçam no ambiente escolar pelo pensarfazer dos professores, exige dos professores uma ressignificação do currículo e das políticas oficiais do sistema educativo. Dessa forma:

falar em currículo como criação cotidiana pressupõe, entre outras coisas, que as diferentes formas de tecer conhecimentos - que estão na base de diferentes modos de 
agir, mesmo que jamais de modo linear - dialogam permanente umas com as outras, dando origem a resultados tão diversos quanto provisórios. (OLIVEIRA, 2016, p. 97).

A relação entre currículo e cotidiano ganha traços reais a partir das redes de conhecimentos vividas no interior da escola, fundamentalmente aquelas que se articulam entre professores e alunos. Essas redes darão sentido à formação do aluno a partir da sua vivência, que é carregada de artefatos culturais, seja fora ou dentro da escola. É a partir da interface entre os conhecimentos curriculares e o cotidiano vivido pelos aprendizes que delineia-se um processo formativo.

O trabalho docente, na perspectiva da emancipação dos educandos, reinterpreta o currículo oficial, construindo um currículo próprio que considera os artefatos culturais da comunidade escolar articulados com a prescrição normativa curricular. Dessa maneira, professores:

[...] criam currículos e conhecimentos ao trazer para o universo dos conteúdos formais, outros conhecimentos, valores, crenças e convicções que, articulados aos primeiros (conhecimentos formais), dão origem a redes de conhecimentos e a currículos que levam a efetivos processos de tessitura de conhecimentos pelos alunos [...] (OLIVEIRA, 2016, p. 115)

Assim sendo, visibilizar os conhecimentos invisíveis presentes no cotidiano escolar é fundamental para pensar o currículo como uma criação cultural. Essa forma de criação potencializa os sujeitos para a luta contra a hegemonia de um discurso legitimador de uma classe dita "superior". Esse discurso hegemônico impõe os tipos de conhecimentos a serem inseridos nos currículos e aplicados e aprendidos pelos alunos.

Considerar os conhecimentos presentes nos currículos oficiais e os conhecimentos presentes nos espaçostempos das escolas possibilita aos docentes criar mecanismos para harmonizar essa relação. Permite tornar o conhecimento acessível àqueles que dele necessita para a sua emancipação. É o que chamamos anteriormente de táticas dos mais fracos frente ao que é organizado oficialmente e que determina o que deve ser ensinado. No entanto, sabemos que os currículos pensadospraticados precisam ser adaptados ou reconfigurados, conforme as realidades específicas, para atender as necessidades ali presentes.

Quando analisamos a compreensão de currículo dos professores nas suas práticas docentes, entendemos que existe uma lucidez em relação a isso. Eles dimensionam a importância de se valorizar os currículos existentes no ambiente educacional como elemento fundamental para a formação do indivíduo e da sociedade. Assim, a compreensão dos professores não se limita apenas à prescrição, mas estende-se ao cotidiano escolar. Assim nos mostra o Professor Francisco, sobre as construções que se dão no cotidiano escolar:

Prof. Francisco: São práticas, são vivências, são crenças que são constituídas e construídas no saber da própria instituição, da própria escola. São conjuntos de saberes epistemológicos e científicos, aquelas coisas todas que nós já sabemos, que vêm no sentido de estruturar, de organizar um...[pausa] de estruturar um programa direcionado à prática e também a saberes teórico-científicos.

A fala do professor nos leva a refletir sobre algumas vertentes teóricas relativas aos estudos curriculares. Uma delas é que, ao mergulharmos nas práticas e nos vários estudos publicados, percebemos que o currículo prescritivo apresentado pelo Estado acaba prevalecendo sobre os demais presentes no ambiente educacional. O currículo prescritivo, nos diz o Professor José, "é uma ação pedagógica, é um documento, é um subsídio que vai te ajudar a direcionar as suas práticas pedagógicas docentes. Pronto, esse é um currículo e para que serve, é um documento."

Além de ser visto como uma ação pedagógica, o currículo pode nos direcionar para o compreendermos como um instrumento que alicerça e direciona o trabalho do professor, como nos diz a Professora Maria:

Profa. Maria - Para mim, currículo é aquilo que vai orientar o meu trabalho pedagógico, é o que orienta mesmo, tipo assim, ele não tem tudo lá, mas a base está lá no currículo, e daí eu olho para lá, vejo o que tem lá, e baseio todo o meu trabalho do ano letivo, a 
construção do meu plano, a construção das minhas sequências [didáticas] a partir do meu plano. Então, esse currículo baseia o meu trabalho pedagógico, mas eu o trago para a realidade do estado, da cidade, do bairro em que minha escola está inserida.

É importante ressaltar que há um cuidado dos professores em entrelaçar suas práticas de ensino com o conhecimento cultural dos alunos, demonstrando a compreensão de que currículo não é somente aquilo que já vem estruturado como lei a ser aplicada de maneira direta. Essa compreensão mais ampla de currículo, que entrelaça o aspecto cotidiano e o aspecto prescritivo, perpassa toda a situação capaz de produzir conhecimentos significativos, como aponta a Professora Antônia:

Profa. Antônia - Currículo nós vamos construindo com a nossa prática, com nossa metodologia diária. Então a gente percebeu que deu resultado. Aí é a construção do nosso currículo. Nós podemos dizer que currículo é a nossa prática diária, nossa construção diária de saberes, de conhecimento dos nossos alunos, o que nós podemos mostrar para eles de novo.

É preciso olhar para os anseios e questionamentos vindos e vividos do real, do dia a dia dos alunos e professores. De formas bem ativas, professores e alunos tornam as salas de aulas verdadeiros laboratórios de conhecimento. Através do diálogo, criam mecanismos de aprendizagem capazes de ampliar visões e de superar problemas do cotidiano. Dessa forma, as práticas docentes ganham mais dinamismo, pois o conhecimento sempre estará atrelado às dúvidas e aos questionamentos que surgem.

As indagações oriundas do cotidiano merecem atenção por tratarem de situações vividas e que, portanto, merecem soluções imediatas, longe, muitas vezes, de serem resoluções prontas ou definitivas. Por isso, o currículo deve ser aberto e atento às dinâmicas que a aprendizagem e seu contexto oferecem. Quando falamos do currículo aberto, estamos ressaltando que é possível e necessário respeitar os valores que circulam no ambiente específico dos professores.

Dizemos, portanto, que é preciso dar atenção às problemáticas que se entrecruzam num contexto de sala de aula que, para que sejam superadas, exigem do professor a busca de elementos para além da formalidade. O Professor Lucas pontua com precisão esse caráter contextual da prática docente:

Prof. Lucas - Uma das situações bacanas que o currículo tem é ele ser flexível. Assim, a Base [BNCC] traz os seus conteúdos, porém, se a gente for analisar a fundo, aqueles conteúdos que estão na Base, eles não são assim, aqueles conteúdos que você acha como chave para dar para a vida do aluno.

Os professores estão potencialmente atentos a esse dinamismo, mas ainda lutam por autonomia dentro de sala para usarem a sua criatividade. Eles encontram nas Secretarias de Educação uma resistência, um posicionamento que os direciona a seguir o currículo fechado. Por isso, é importante usar a criatividade como metodologia de aulas que contemplem as diversidades ali presentes. É preciso que os professores, a escola e toda a equipe gestora olhem na direção da aprendizagem significativa, capaz de transformar os sujeitos e suas realidades sociais.

O modo como são estabelecidas as tessituras do pensarfazer de professores e alunos dá sentido a um currículo desejado a partir de um espaçotempo. Esse currículo pode ser modificado a partir da compreensão do processo educativo como caminhada formativa e emancipadora de sujeitos críticos. Essa dinâmica pode gerar ações no interior da escola a partir da prática social dos indivíduos lá situados.

Nessa perspectiva, o currículo vivido pelos professores e alunos no cotidiano escolar não se torna estático, mas adquire uma dinâmica de (re)criação dos conhecimentos. Esse processo ocorre por meio do pensarfazer no contexto de um espaçotempo próprio da instituição escolar. Isso não requer perder de vista a interferência das políticas nacionais, num sentido amplo, e, particularmente, das políticas educacionais. O currículo passa a ser entendido, desse modo, como uma ação:

[...] intencionada, emocionada, prazerosa devolve aos sujeitos da escola sua dignidade de criadores, sujeitos ativos de seus fazersaberesprazeres, únicos, singulares, embora mergulhados num mundo social (cognitivo) que os ultrapassa, mas que também é por eles tecido (OLIVEIRA, 2016, p. 51 - grifo no original). 
A vivência do cotidiano escolar dá-se nessa relação prazerosa de aprendizagem. É por meio das interações ocorridas no interior da escola que os indivíduos tomam consciência de que a construção curricular cabe a eles, mesmo que prescritivamente venha das políticas de governo. No cotidiano, ocorre a ressignificação em busca de práticas emancipatórias, sobretudo quando pensadas nos movimentos entre as táticas e estratégias.

Estratégias e táticas não podem ser vistas de forma dissociada no contexto educacional. As estratégias aplicadas pelos grupos hegemônicos no poder desencadeiam em cada setor um agrupamento dos profissionais que é circunstancial. Por meio de uma compreensão, eles mobilizam um conjunto de táticas para o enfrentamento e para as resistências a essas estratégias. Como diz Certeau:

[...] as táticas são procedimentos que valem pela pertinência que dão ao tempo, as circunstâncias que um instante preciso de uma intervenção transforma em situação favorável, a rapidez de movimento que muda a organização do espaço, as relações entre momentos sucessivos de um "golpe", aos cruzamentos possíveis de duração e ritmo heterogêneos etc (CERTEAU, 1998, p. 102).

As táticas, como elemento dos mais fracos, não determinam as formas de vida social, mas como elas acontecem. Isso fica claro quando chegamos na escola e identificamos ações dos professores que alteram as prescrições para que as aprendizagens aconteçam. As táticas e as estratégias são elementos históricos que permeiam os muros da escola e se estabelecem nos meios sociais, nos espaçostempos em que as redes de conhecimentos se materializam.

As redes de conhecimentos, que se entrecruzam nos espaçostempos, facilitam reelaborar táticas quando o programado é, de um modo ou de outro, inviável de ser aplicado. Nesse sentido, o Professor Paulo relata sobre uma experiência que tiveram no Dia da Consciência Negra:

Prof. Paulo - Tinha a aula sobre a Consciência Negra [...], choveu e aí tinha poucos alunos. Então, como era dia 20 de novembro, a gente iria falar sobre o Dia da Consciência Negra. E o que fazer agora [com a chuva]? Aí colocamos os alunos do $1^{\circ}, 2^{\circ}$ e $3^{\circ}$ anos todos numa mesma sala, e, de repente, a Cris falou, "e o Dia da Consciência Negra?", aí a gente, "tá”... aí o Adalberto falou: "eu tenho um filme, eu tenho", aí nós juntamos todas as salas, e aí começamos a trazer o diálogo da Consciência Negra, conversar sobre o filme, apresentar a história um pouquinho, e foi legal, que eles gostaram, participaram. Nós assistimos os vídeos, eu acho que ouvimos músicas sobre eles. [Isso] trouxe uma reflexão muito grande para a gente, o que me surpreendeu, foi um plano assim, de imediato, que conseguimos e deu super certo.

Essas táticas utilizadas pelos professores para não perderem o dia de aula, representam o esforço e o compromisso de cada um com a escola, com as suas profissões, e, em especial, com os alunos, a parte mais importante nessa história. O reinventar na escola acontece todos os dias. Ele é movido pelos comportamentos externos e até mesmo a partir da reflexão realizada sobre o próprio trabalho do professor. O Professor Lucas destaca uma mudança de postura na sala para superar um problema de conduta dos alunos:

Prof. Lucas - Quando eu chegava nas salas, as vezes, [havia] muito papel no chão [...], aí eu coloquei umas normazinhas lá, valendo como se fosse um trabalho da disciplina, eu não faria uma atividade de disciplina valendo uns seis pontos. Todo aluno começa com seis pontos o bimestre, e ele pode ir perdendo ao longo do bimestre, tipo, se você jogar lixo no chão, e eu ver e você não juntar, você perde meio ponto, se xingar o colega, falar palavrão, perde meio ponto. Na minha aula, a sala passava o dia inteiro limpa, porque eles sabem que se eles fizerem aquilo eles vão sofrer algum tipo de punição, por não seguir aquilo que, ao meu ver, é necessário, você pegar o lixo e jogar no lixo; você não esconder algo do colega que está precisando, por exemplo, da caneta, amarrar a mochila do colega na cadeira. São coisas simples que eles... a gente sabe que é um tipo de brincadeira, mas chega um ponto que alguém vai ficar chateado, vai acontecer uma discussão.

Na escola, também nos responsabilizamos pela construção de bons costumes e no respeito para com o outro. Essas posturas são tão importantes quanto as acadêmicas formais. Em outros termos, 
implica dar visibilidade aos invisíveis, valorizar seus atos para que a partir dessa situação gere-se um bom comportamento. Nesse sentido, os professores buscam meios que fogem ao prescrito pelas leis e criam mecanismos para melhor lidar com situações práticas, como nos conta o professor Lucas:

Prof. Lucas - O aluno fica andando em sala sem precisão, ele vai perder meio ponto. "Professor, eu quero falar com um colega ali”, "vai lá, tranquilo”, mas ficar andando em sala para quê? Atrapalhando o colega que está concentrado? Na hora da explicação, silêncio total, por quê? Se atrapalhar a explicação do professor, a colocação do colega durante a explicação, perde meio ponto, porque eu tenho que ouvir e tenho que interagir na aula. Ou seja, a aula correu normalmente bem, porque eles sabiam que eles iriam perder alguma coisa. Eu não sei se é uma coisa positiva, mas eu fiz isso e deu certo. Mas, não está previsto no modelo, é só uma forma de atrair eles mais para a aula.

O que está por trás dessa norma estabelecida pelo Professor Lucas é a preocupação com a aprendizagem. Trata-se de uma ação para dar visibilidade ao aluno pelas suas boas ações e não por comportamentos desrespeitosos. Trata-se de oportunizar que tragam para as aulas suas experiências e histórias.

Essas ações utilizadas pelos professores são táticas para ressignificar o currículo oficial. Valorizar os artefatos culturais produzidos cotidianamente pelos atores do processo escolar, numa perspectiva de transitoriedade, pode ser percebido como uma resistência. Isso pelo fato das táticas serem, necessariamente, (re)elaboradas a partir do dos contextos, tal como eles se apresentam. Nessa perspectiva, cabe ao investigador estar atento para compreender o movimento transitório da aplicabilidade dos conhecimentos, a partir das táticas e ações escolhidas pelos protagonistas que vivem esse cotidiano.

As estratégias, no contexto do cotidiano escolar, podem ser entendidas como políticas educacionais macro, que partem de uma compreensão da classe política hegemônica. Portanto, são marcadas por uma concepção de dominação, carregadas de um poder implícito de obrigatoriedade e de aplicabilidade nas instituições escolares, independente de seus contextos. São, portanto, políticas oficiais normativas.

De outro modo, as táticas, dentro do meio educacional, devem ser compreendidas como ações dos profissionais de educação, em particular dos professores. Elas caracterizam-se como uma resistência às prescrições normativas das políticas governamentais. As táticas são ações circunstanciais desencadeadas a partir da tomada de consciência dos professores frente às imposições das políticas oficiais. Não constituem-se como um agrupamento de medidas coeso, de longo prazo. São marcadas pela transitoriedade das compreensões desses professores, das políticas governamentais e dos grupos políticos que ocupam o poder e definem as políticas oficiais.

\section{A CONSTRUÇÃo CURRICULAR E AS POLÍTICASPRÁtICAS}

"Não há prática que não integre uma escolha política e que não há política que não se expresse por meio de práticas e que por elas não seja influenciada." (OLIVEIRA, 2013, p. 2)

Com a epígrafe que trazemos acima, ilustramos nossa trajetória epistemológica. Ela evidencia que o termo "políticaspráticas", aglutinado, não é de nossa autoria, mas da autora da epígrafe, exatamente para mostrar que não há política sem prática e não há prática sem política. As categorias não são finitas nelas mesmas. Trazem consigo muitos sentidos e significados, que, as vezes, nos dizem muito mais do que qualquer frase ou palavras.

Ainda em relação à frase que norteia essa reflexão, é parte de nossa inquietação, quando em contato com os textos da autora, que o currículo como política é prático e a prática vira política quando desinvisibilizamos os conhecimentos presentes no cotidiano. Essa é uma noção de que o currículo costuma estar associado ao ensino, porém sem aporte na aprendizagem, mas que podemos expressar a concepção de currículo do ponto de vista de quem faz e não de quem executa ou que por ele é "moldado". 
O termo moldado aparece, aqui, com um sentido pejorativo ao mostrar que há uma forte tendência de prevalência da concepção de currículo mais prescritivo. Nossa concepção epistemológica está muito próxima do que apresenta Oliveira (2016), uma vez que entendemos currículo como elemento de emancipação do sujeito, que considera os aspectos de sua realidade, que possibilita outras visões de mundo, sem que haja uma hierarquização dos conhecimentos.

A visão da autora nos remete a algumas categorias discutidas por Santos (2006), especificamente no texto "Para uma sociologia das ausências e uma sociologia das emergências". Essa teoria nos ajuda a entender a concepção de política curricular e como são organizadas as políticas educacionais tidas como científicas, laboratoriais. Essa modalidade de política não valoriza ou não compreende como apropriadas as práticas tecidas cotidianamente e reconstruídas em sala de aula e para além dela.

Nesse sentido, conforme Santos (2007) e Gonçalves (2018a) apontam, a "sociologia das ausências" aparece como forma de enfatizar práticas e conhecimentos que são deixados à margem, que são ignorados pelos conhecimentos científicos. Sendo assim, é preciso "vislumbrar alternativas e potencialidades emancipatórias ainda-não existentes” (GONÇALVES, 2018a, p. 66). Isso é necessário para que nossas práticas sejam reflexivas e para que os sujeitos por ela contemplados, e que dela participam, consigam dar existência e voz a novos conhecimentos.

Esse percurso, de olhar "o currículo como uma construção do cotidiano" (Oliveira, 2016), nos chama a atenção para a razão indolente, tal como a definiu Boaventura de Souza Santos. O autor nos apresenta quatro modelos de razão que merecem ser apresentadas, a saber: $a$ razão impotente, a razão arrogante, a razão metonímica e a razão proléptica (SANTOS, 2007).

O termo indolente, gramaticalmente falando, significa ausência de dor, insensível, negligente. Essa definição é consubstancialmente similar nas análises de Santos (2007), Oliveira (2016) e Gonçalves (2018; 2020). Ela faz parte da resistência para quebrar o pensamento hegemônico, presente nessa forma de razão, para dar voz ao conhecimento verdadeiro e invisível que é rechaçado por ela. No âmbito do endeusamento do conhecimento científico, ela não democratiza as experiências como sendo, também, conhecimento.

Consolidada pela cultura dominante e alimentada pelas instituições que alimentam as hegemonias, a razão indolente vê-se justificada na razão proléptica e na razão metonímica discutidas por Boaventura de Souza Santos. A razão metonímica busca invisibilizar a diversidade de práticas sociais de conhecimento do mundo por meio de uma contração do presente; a razão proléptica, por sua vez, busca instaurar uma abdicação indolente que expande o futuro, supondo já conhecê-lo por considerá-lo a repetição do presente em evolução linear.

Assim, temos a noção de que vivemos o tempo presente em prol de um futuro que ainda não alcançamos e, nessa compreensão, a razão proléptica atua concebendo um futuro que não precisa ser pensado, uma vez que, abundante e infinitamente igual, ele somente existe para se tornar passado. (GONÇALVES, 2018a).

Com isso, percebemos que há dois movimentos bastante claros e importantes para pensarmos nossas produções cotidianas de conhecimento. O primeiro movimento é o de descontruirmos a ideia de que a parte representa o todo do conhecimento. Essa noção acaba desinvibilizando as produções cotidianas que alargam as possibilidades de pensarmos a escola também como campo de produção. $O$ segundo movimento nos coloca diante de estratégias não hierarquizantes. É importante protagonizar as experiências e sensações produzidas nas relações mais corriqueiras do cotidiano e que são capazes de emancipar os sujeitos frente às questões e aos problemas existentes em suas trajetórias.

Assim traremos algumas concepções de currículos para entendermos, a partir dessas definições, como as construções curriculares são produzidas e como essas visões alteram substancialmente o projeto de sociedade que desejamos.

O currículo não pode mais ser visto apenas como a organização do conhecimento escolar (MOREIRA; SILVA, 2011). É preciso que haja uma compreensão de seu contexto histórico e social para entendermos que o currículo se tornou um campo de disputa, uma vez que pode influenciar diretamente 
ISSN $1983-1579$

Doi: 10.22478/ufpb.1983-1579.2020v13n3.52791

http://periodicos.ufpb.br/ojs2/index.php

na construção de um projeto de sociedade. Nesse sentido, Moreira e Silva (2011) realizam um trabalho mostrando como os estudos sobre o currículo vão evoluindo, a partir da Nova Sociologia da Educação, e de que maneiras as instituições vão se organizando conforme as tendências. Para tanto, nos apresentam três eixos, ideologia, cultura e poder.

Currículo e ideologia pareciam elementos distintos ou que não se coadunavam, haja vista que a concepção de ideologia era puramente idealista, não se materializava. Essa ideia começa a mudar, segundo Moreira e Silva (2011), com Althusser, em seus ensaios “A ideologia e os Aparelhos Ideológicos do Estado”. O francês nos mostra que a visão de ideologia como falsa ideia da realidade nos conduz ao binarismo epistemológico em que o que é ideológico é falso, e o que não é ideológico é verdadeiro. Porém, nos aponta o autor que essa visão é deturpada. Precisamos entender alguns elementos que fazem parte do processo de composição/formulação da ideologia para entendemos que ela segue alguns ritos bem mais materializados do que imaginava a sociedade.

Destacam-se aqui três pontos cruciais, sendo o primeiro deles que não podemos ver a ideologia como um elemento de imposição que vem de cima para baixo. Ela é construída com elementos e fragmentos de elementos que estão presentes no senso comum. O segundo ponto é que a ideologia não é um elemento homogêneo, único, mas construída de várias ideias, vários elementos e conhecimentos de natureza diversa. E por fim, como terceiro ponto, destaca-se que não há ideologia se não houver resistência.

Com isso, entendemos que a ideologia está muito mais ligada ao currículo do que se imaginava. Ela perde seu matiz idealista e passa a ser vista por muitos estudiosos como parte do próprio ritual de organização do conhecimento.

Outro ponto importante para entendermos a construção curricular está ligado à ideia de currículo e cultura. Numa visão crítica, não podemos ver como elementos que se misturam, mas separados, para além da ideia de que o conhecimento organizado curricularmente é apenas uma mera reprodução da cultura existente. Também não cabe a compreensão de que a cultura seja uma transmissão dos conhecimentos dos mais velhos para os mais jovens. Ela é algo dinâmico que interage com o contexto, com as pessoas ali presentes e com a história, numa ideia de construir conhecimentos com base não na mera reprodução.

Vale destacar, ainda, que o professor é capaz de romper com essa ideia do currículo como poder. É capaz de flexibilizar de acordo com os vários espaçostempos em que ele se materializa, tal como nos dizem a Professora Joana e o professor Lucas:

Profa. Joana - A gente tem que adaptar os conteúdos que venham a trazer algo para a realidade dele [aluno], para a vida dele, alertar, fazer com que aquele aluno se torne mais ativo no seu meio, na escola, no seu meio também. Por quê? Porque eles ficam muito presos na questão do eu, do individual, seja mais social, seja mais aberto, seja mais humilde, principalmente... eu trabalho muito a questão da humildade, da empatia, de você querer sempre ajudar o próximo.

Prof. Lucas - Vários conteúdos da Base [BNCC], [...], digamos assim, não [são] do mercado de trabalho, mas mais na questão formal daquilo que tem que ser passado, porque isso vai ter resultado nisso, e deixa a questão social um pouco de lado.

O que vemos, quando falamos de cultura é, mais uma vez, uma luta entre as classes e disputas sobre que tipos de conhecimentos devem ser selecionados e organizados para serem ensinados. Desse modo, não podemos aglutinar currículo e cultura. No entanto, nossa visão de currículo deve levar em consideração esse elemento para criamos situações de emancipação do sujeito.

Se levarmos em consideração que o poder implica em estabelecer uma subordinação a outrem, podemos dizer que o currículo está no centro dessa questão. Isso porque, quando falamos do currículo como a prescrição de um conhecimento a ser transmitido, é claro que ele vem perpassado de relações de poder e de determinações de um grupo sobre outro. Ainda que haja questionamento quanto ao conteúdo 
dessas prescrições, elas são vistas como "importantes" e que precisam ser transmitidas aos seus destinatários.

Romper com a ideia de poder e adaptar o currículo, sob a forma de conteúdos e de práticas, nas várias realidades, é buscar uma formação voltada para o desenvolvimento do sujeito mediante suas necessidades. Portanto, buscar uma formação mais humana e menos mercadológica. É ver que a educação pode e deve mudar a vida das pessoas.

\section{FINALIZANDO (POR HORA) NOSSA CONVERSA}

As compreensões de currículos tecidas pelos professores na pesquisa nos colocam diante de algumas reflexões de cunho epistemológico. Partimos da convicção de que o currículo é uma criação cotidiana (OLIVEIRA, 2016) e que, portanto, não está condicionado a uma visão centralizada e fechada. Diante do fato de pensarmos o currículo como uma construção ligada às experiências que o cotidiano nos proporciona, podemos entender que as políticas curriculares são instrumentos que definem, mas, também são definidas e ressignificadas pelas práticas pensadasvividas.

Não podemos apagar as diferenças frente à construção do conhecimento, já que esse se forma exatamente nessas diferenças, dando vida e voz aos que historicamente não eram vistos como produtores de conhecimento. Ainda que haja uma política governamental normativa que se materializa no ambiente escolar, é no pensarfazer, na (re)criação e nas táticas que os professores utilizam todos os dias, quando desenvolvem seus trabalhos, que deve ser estabelecido o currículo escolar.

\section{REFERÊNCIAS}

CERTEAU, Michel de. A invenção do cotidiano: artes de fazer. Petrópolis: Vozes, 1994.

GONÇALVES, Rafael Marques. Bricolagens praticadas e políticaspráticas de currículos nos cotidianos escolares. 2018. Tese (Doutorado em Educação) - Universidade do Estado do Rio de Janeiro, Rio de Janeiro, 2018a.

GONÇALVES, Rafael Marques. Autonomia e políticaspráticas de Currículos: uma equação entre raízes e opções. Revista Educ. Real., Porto Alegre , v. 44, n. 3, e84870, 2019. Acesso em 26 maio 2020. Epub Sep 12, 2019. https://doi.org/10.1590/2175-623684870

GONÇALVES, Rafael Marques; et at all. A BNCC na contramão das demandas sociais: planejamento com e planejamento para. Práxis Educacional, [S.I.], v. 16, n. 38, p. 338-351, jan. 2020.. Acesso em: 26 maio 2020. doi: https://doi.org/10.22481/praxisedu.v16i38.6012.

GONÇALVES, Rafael Marques. Conversas sobre práticas e currículos entre professoras: artesania e maneiras de fazer o cotidiano escolar. Linguagens, Educação e Sociedade, Teresina, Ano 23, Edição Especial, dez. 2018. Acesso em 26 de maio de 2020. Doi: https://doi.org/10.26694/les.v1i1.7876

MOREIRA, Antônio Flávio; SILVA, Tomaz Tadeu. (Orgs). Currículo, cultura e sociedade. São Paulo: Cortez, 2011.

OLIVEIRA, Inês Barbosa de. Boaventura e a educação. Belo Horizonte: Autêntica, 2006.

OLIVEIRA, Inês Barbosa de. Currículo e processos de aprendizagemensino: políticaspráticas educacionais cotidianas. Currículo sem Fronteiras, v. 13, n. 3, p. 375-391, set. /dez. 2013.

OLIVEIRA, Inês Barbosa de. O currículo como criação cotidiana. Rio de Janeiro: DP et Alii, 2016.

SANTOS, Boaventura de Sousa. Pela mão de Alice: o social e o político na pós-modernidade. São Paulo: Cortez, 2006.

SANTOS, Boaventura de Sousa. A crítica da razão indolente: contra o desperdício da experiência. São Paulo: Cortez, 2007.

SANTOS, Boaventura de Sousa. A gramática do tempo: para uma nova cultura política. São Paulo: Cortez, 2008. 
ISSN $1983-1579$

Doi: 10.22478/ufpb.1983-1579.2020v13n3.52791

http://periodicos.ufpb.br/ojs2/index.php

Recebido em: 26/05/2020

Aceito em: 30/09/2020

Publicado em: 09/11/2020 